\title{
Influence of Ortho Primer Morelli adhesion booster on orthodontic brackets shear bond strength
}

Sabrina de Mendonça Invernici', Ivan Toshio Maruo², Elisa Souza Camargo ${ }^{3}$, Thais Miyuki Hirata', Hiroshi Maruo ${ }^{4}$, Odilon Guariza Filho ${ }^{3}$, Orlando Tanaka ${ }^{4}$

Objective: This work aimed at assessing the bond strength (AS), the site of the flaw and the relation between them and Ortho Primer Morelli ${ }^{\circledR}$ (OPM) adhesion optimizer.

Methods: Sixty test specimens, made out of bovine permanent lower incisors, were divided into three groups: TXT Primer (control), in which a conventional adhesive system was applied (primer and paste); OPM, in which TXT primer was replaced by OPM; and TXT without Primer, in which only TXT paste was used. A shear force was applied at a speed of 0,5 mm/min. Failure site was assessed by the Remaining Adhesion Index (RAI).

Results: Kruskal-Wallis demonstrated that OPM $(8.54 \pm 1.86 \mathrm{MPa})$ presented a statistically higher AS ( $<<0.05)$ IF compared to TXT Primer ( $6.83 \pm 2.05 \mathrm{MPa})$. There was no statistically significant difference $(\mathrm{p}>0.05)$ between TXT with or without Primer ( $6.42 \pm 2.12 \mathrm{MPa})$. Regarding the RAI, the K test demonstrated that TXT Primer and OPM (prevailing scores 2 and 3 ) showed higher values $(\mathrm{p}<0.05)$ IF compared to TXT without Primer (prevailing scores 0 and 1). Spearman demonstrated that there was no correlation between AS and RAI $(p>0.05)$.

Conclusion: OPM increases AS and presents the same bond failure location if compared to a conventional adhesive system; the use of the TXT adhesive system paste only was shown to have the same AS if compared to conventional systems, except it does not allow to predict the adhesive failure site; there is no correlation between AS and bond failure location, regardless of the use of any adhesion optimizer.

Keywords: Primer. Adhesion. Shear adhesive strength.

${ }^{1}$ Specialist in Orthodontics, PUC-PR

${ }^{2} \mathrm{PhD}$ student in Orthodontics, PUC-PR.

${ }^{3}$ Associate Professor of Orthodontics, PUC-PR.

${ }^{4}$ Full Professor of Orthodontics, PUC-PR.
How to cite this article: Invernici SM, Maruo IT, Camargo ES, Hirata TM, Maruo H, Guariza Filho O, Tanaka O. Influence of Ortho Primer Morelli adhesion booster on orthodontic brackets shear bond strength. Dental Press J Orthod. 2012 May-June;17(3):31-9.

Submitted: August 25, 2008 - Revised and accepted: September 29, 2009

» The authors report no commercial, proprietary or financial interest in the products or companies described in this article.

Contact address: Elisa Souza Camargo

Rua Fernando Simas, 327 - Curitiba/PR - Brazil

Zip code: 80.430-190 - E-mail: elisa.camargo@pucpr.br 


\section{INTRODUCTION}

The bonding of orthodontic brackets was first attempted by Newman ${ }^{16}$ and has become a clinically accepted technique since 1970, when new dental bonding agents started to be developed in pursue of accomplishing higher adhesion to either enamel or dentin. Bonded brackets have replaced teeth banding, and this technique is quite superior in maintaining gingival and dental health, as well as better esthetics. ${ }^{10}$

Adhesion procedures are based on enamel surface changes created by acid etching, developed by Buonocore. ${ }^{3}$ Obtaining an efficient adhesion between orthodontic brackets and the bonding surface of teeth, by means of a good bonding system, is of great benefit to orthodontic treatments. The efficiency offered by bonding systems is paramount to the adhesion of orthodontic pieces, since loose brackets during treatment mean lost money for both patients and dentists. ${ }^{21}$

Many different products have been launched on the market as an attempt to increase bonding agent's adhesive strength, and studies about bonding optimizers have become quite common in the literature. ${ }^{17}$ According to Reynolds, ${ }^{19}$ bonding agents applied between acid etching and resin increase enamel adhesion. Nevertheless, other authors ${ }^{4,5,18}$ did not observe any increase in the adhesive strength when comparing conventional and primer based systems.

It can therefore be observed that not all published pieces of research take for granted the real potential of bonding optimizers in order to increase adhesive strength. This lingering concern has fostered the study about adhesive strength of a material recently launched in the market by Morelli $^{\circledR}$, which is presented as a light cured acrylic based adhesion promoting agent, with hydrophilic properties, pointed out as an adjunct to bonding both metallic and ceramic brackets.

\section{MATERIAL AND METHODS}

Ninety bovine lower permanent incisors without enamel alterations were obtained. After soft tissue removal, crowns were separated from the roots and kept in $0.1 \%$ thymol water solution, under room temperature (approximately $37^{\circ} \mathrm{C}$ ).

Teeth segments $(5 \times 5 \mathrm{~mm})$ were severed from the flattest buccal surfaces with a carborundum disc and cooling water spray. A clay sphere was manufactured and was pressed between two glass slabs, with a $1 \mathrm{~mm}$ thick stainless steel clamp (Figs 1B - E) in order to obtain a standardized thickness. Each tooth segment was pressed against the glass slab and fixed with clay in order to have the enamel flattest surface in contact with the slab (Figs $1 F, G)$. An aluminium ring (24 mm diameter x $20 \mathrm{~mm}$ height) was placed over the glass slab, centralizing the tooth segment inside it (Fig $1 \mathrm{H})$. Transparent self-cured acrylic resin was manipulated and poured inside the aluminium ring ( $24 \mathrm{~mm}$ diameter x $20 \mathrm{~mm}$ height), which had its inner surface insulated with petroleum jelly (Figs 1I, J). After acrylic resin full set, test specimens were removed from the rings and rinsed under running water (Figs $1 \mathrm{~L}-\mathrm{O}$ ).

\section{Bracket bonding}

Once a good prophylaxis was performed with pumice powder and water, applied with a rubber cup, during 10 seconds, over all exposed enamel surfaces, teeth were washed with water spray for $10 \mathrm{sec}$ and blown dry for another 10 seconds at $5 \mathrm{~cm}$ distance, using a moisture and grease free air syringe. Rubber cups were replaced every 5 test samples.

After that, enamel surfaces were etched with $37 \%$ phosphoric acid for $15 \mathrm{sec}$, rinsed for $15 \mathrm{sec}-$ onds and blown dry for another $15 \mathrm{sec}$ with the air syringe at a $5 \mathrm{~cm}$ distance.

Sample division into three groups proceeded, each one containing thirty test specimens, according to specifications below:

» Transbond $\mathrm{XT}^{\circledR}$ Primer Group (control group) - A layer of Transbond XT ${ }^{\circledR}$ (3M Unitek) primer was applied over enamel etched surface, followed by a two seconds light air blow, as advised by the manufacturer.

» Ortho Primer Morelli ${ }^{\circledR}$ Group - Ortho Primer Morelli ${ }^{\circledR}$ was used in this group according to manufacturer's instructions, that is, a thin layer of primer applied on both bracket and etched enamel, replacing the primer from Transbond $\mathrm{XT}^{\circledR}$ composite.

» Transbond $\mathrm{XT}^{\circledR}$ without Primer Group - No primer was applied in this group.

In all three groups, a good layer of Transbond $\mathrm{XT}^{\circledR}$ (3M Unitek) was spread on the base of the orthodontic piece (lower central incisor bracket with $12 \mathrm{~mm}^{2}$ of base dimension - Morelli ref: 10.30.209) and bonded to the teeth. In order to standardize the thickness of the adhesion material, brackets underwent 400 

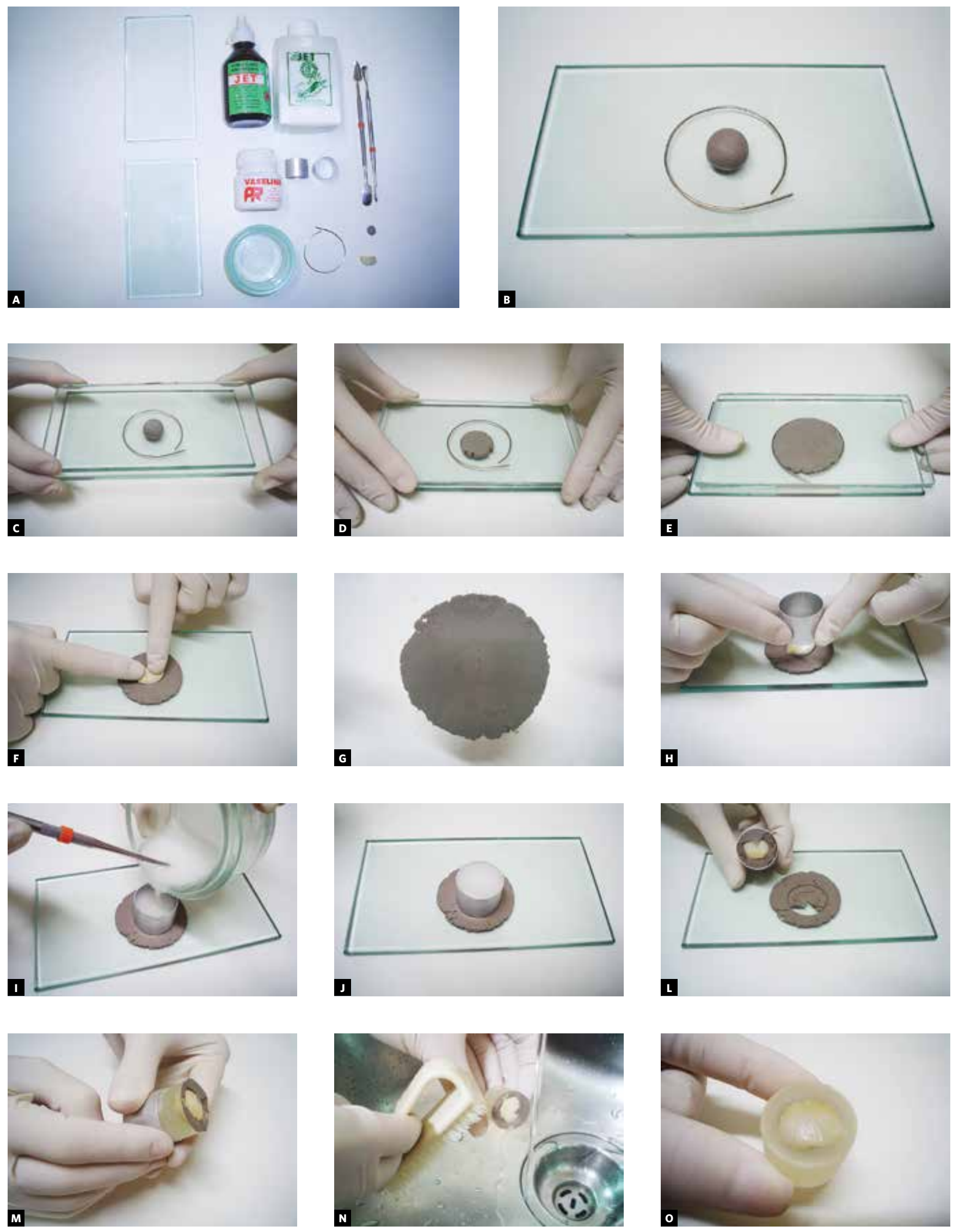

Figure 1 - Test specimens manufacturing. 
grams strength on a dynamometer (Morelli - ref. 75.02.006) (Fig 2). After removing the excesses with an exploratory probe, the material was light cured for 40 seconds (10 seconds for each side of the bracket) at a distance of $2 \mathrm{~mm}$, using Optilux (3M Unitek) as the light source and $630 \mathrm{~mW} / \mathrm{cm}^{2}$ of power.

After light curing, sample specimens were stored in distilled water at room temperature for two hours.

\section{Bracket removal}

In order to assess the adhesive strength (AS), test specimens were positioned and fixed by a stainless steel and threaded bolt device in such a way the brackets slots would be parallel to the shear force thus minimizing the "wing deformation" factor.

Shear test for bracket removal was performed 32 hours after bonding in a EMIC DL500 ${ }^{\circledR}$ Universal Assay Machine (Equipamento de Ensaio Ltda., São José dos Pinhais, Brazil) (Fig 3), in the Laboratory of Characterization and Material Assays of the Mechanical Engineering Course, at Pontifical University of Paraná Technological Park. The speed was 0,5 $\mathrm{mm} / \mathrm{min}$, with a load cell of $50 \mathrm{kN}$ and a computer unit connected to the machine recording the result of the breaking strength (MPa) of each test, considering the basal area of the brackets.

Once removed, brackets and teeth were examined under 10X magnification in a stereoscopic microscope in order to record the remaining adhesive index (RAI), ranked in a 0 to 3 scale (Årtun and Bergland). ${ }^{1}$ Score 0 indicates the absence of material adhered to the tooth; 1 indicates that less than half of the material is still attached to the tooth; 2 indicates that more than half of the material is adhered to the tooth and 3 indicates that all material is still adhered to the tooth, including the bracket mesh print. Scores 0 and 1 indicate an adhesive failure in enamel/adhesive interface, while scores 2 and 3 represent failures in bracket/adhesive interface.

All data were logged and submitted to statistical analysis.

\section{RESULTS}

\section{Adhesive strength (AS)}

Descriptive statistics of the AS variable is presented in Table 1. Considering this variable, groups were assessed for the normality by a Kolmogorov-Smirnov

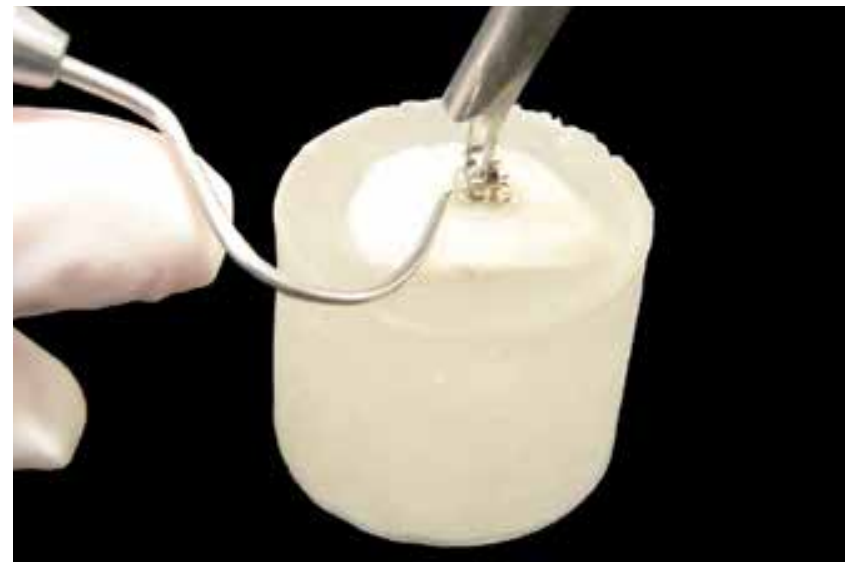

Figure 2 - Bracket being placed under the dynamometer and excesses removed with the probe.

test and for the variance homogeneity by a Lavene test. Only Transbond XT Primer Group did not present a normal distribution.

Therefore, the comparison of AS average values between groups was done through a non parametric Kruskal-Wallis H test, which demonstrated that the AS variable average values were higher for the Ortho Primer Morelli ${ }^{\circledR}$ group, presenting a statistic difference $(\mathrm{p}<0.01)$ when compared to Transbond $\mathrm{XT}^{\circledR}$ Primer and Transbond $\mathrm{XT}^{\circledR}{ }^{\circledR}$ without Primer, although Transbond $\mathrm{XT}^{\circledR}$ Primer and Transbond $\mathrm{XT}^{\circledR}$ without Primer did not present statistic difference between one another $(p>0.05)$.

\section{Remaining adhesive index (RAI)}

Figure 4 presents the RAI frequency distribution amongst the assessed groups. The group with the higher average RAI score was Transbond XT ${ }^{\circledR}$ Primer Group whilst Transbond XT ${ }^{\circledR}$ without Primer was the one with the lower average score. Groups Ortho Primer Morelli ${ }^{\circledR}$ and Transbond $\mathrm{XT}^{\circledR}$ without Primer presented a heterogeneous distribution since Pearson V.C. (\%) variation coefficient exceeded $30 \%$.

Kruskal-Wallis non parametric test revealed that RAI average scores of Transbond $\mathrm{XT}^{\circledR}$ without Primer Group presented statistic difference $(\mathrm{p}<0.01)$ when compared to the other groups, although Ortho Primer Morelli ${ }^{\circledR}$ e Transbond $\mathrm{XT}^{\circledR}$ Primer Groups did not present statistic difference between themselves ( $p>0.05)$. 


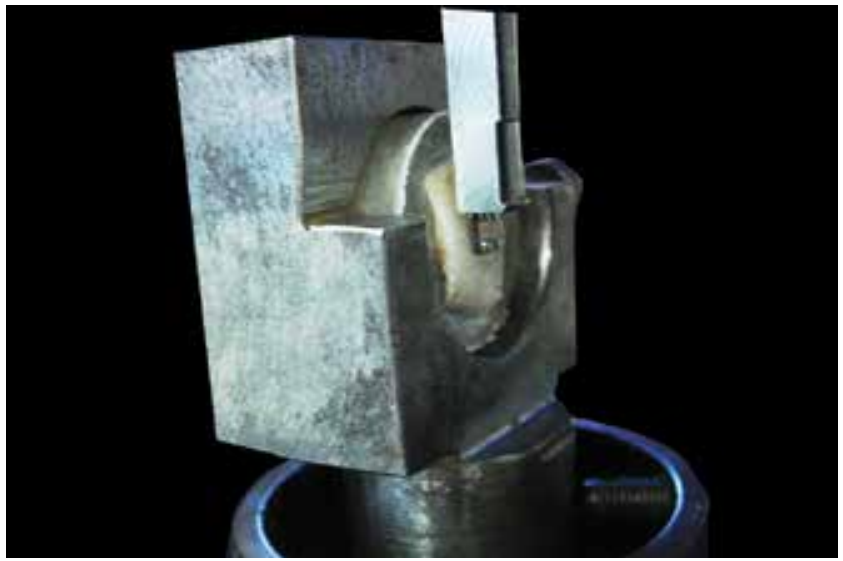

Figure 3 - Shear test in an $\mathrm{EMIC} \mathrm{DL500}{ }^{\circledR}$ testing machine.

\section{Correlation between AS and RAI}

Spearman correlation coefficient calculation between AS and RAI variables presented a value equal to 0.18 , not statistically significant ( $p>0.05$ ), pointing to an absence of correlation between variables AS and RAI.

\section{DISCUSSION}

Bond Enhancing Primers were first launched in the market as an attempt to brackets adhesive strength, which would get loose very often when submitted to masticatory loading, hindering orthodontic treatment results for both patients and clinicians. From a patient standpoint, loose brackets mean longer visits and more discomfort at the dental Office in order to get them fixed, possibly increasing total treatment time. For orthodontists, on the other hand, it means longer clinical sessions dedicated to the office, higher material costs, let alone the delay in concluding the treatment.

Ortho Primer Morelli ${ }^{\circledR}$ studied here is used as a surrogate to primers from the original systems selected for the bonding, and aims at increasing brackets adhesive strength. For this sample, Transbond $\mathrm{XT}^{\circledR}$ adhesive system was chosen as the control since it is universally accepted and considered as excellent quality. ${ }^{2}$

For the in vitro assessment performed in this study, bovine teeth were used given the challenge of gathering extracted human teeth. This is justifiable,
Table 1 - Descriptive Statistics of adhesive strength according to groups.

\begin{tabular}{|c|c|c|c|c|c|}
\hline Groups & $\mathbf{n}$ & Average & Median & $\begin{array}{l}\text { Standard } \\
\text { Deviation }\end{array}$ & V.C. (\%) \\
\hline $\begin{array}{l}\text { Transbond XT } \\
\text { primer }\end{array}$ & 30 & 6.83 & 6.37 & 2.05 & 29.96 \\
\hline $\begin{array}{l}\text { Ortho Primer } \\
\text { Morelli }\end{array}$ & 30 & 8.54 & 8.57 & 1.86 & 21.74 \\
\hline $\begin{array}{l}\text { Transbond XT } \\
\text { without primer }\end{array}$ & 30 & 6.42 & 6.43 & 2.12 & 33.03 \\
\hline
\end{tabular}

V.C. $=$ Variation Coefficient

Source: Research data.

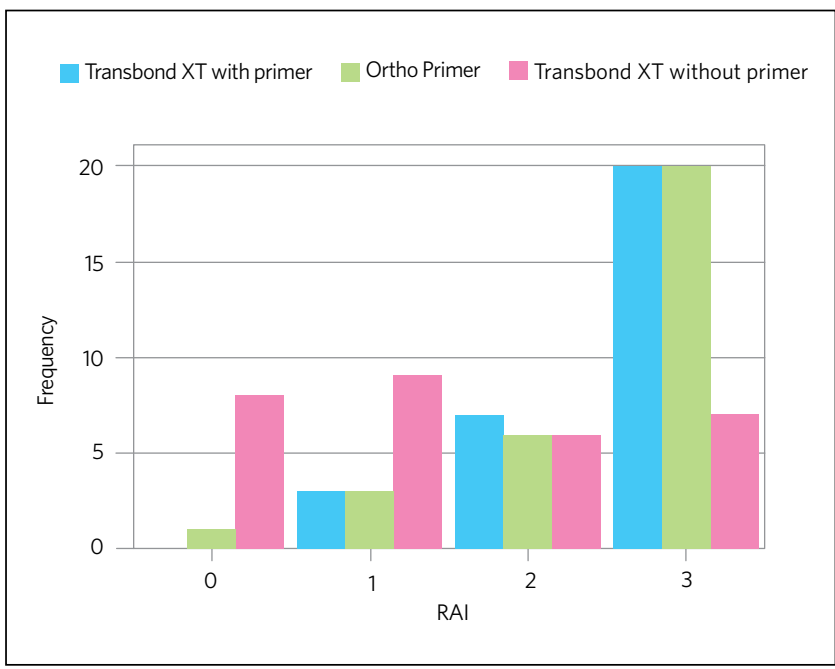

Figure 4 - Remaining adhesive index frequency distribution by groups (Source: PUC-PR, 2008)

since other authors ${ }^{15,17}$ have compared the adhesive strength of composites and cements bonded to both types of enamel and observed no statistic significant difference, although values were slightly lower for bovine teeth.

With regards to test specimens manufacturing, enamel surfaces over which the bonding occurred were not sanded. According to Ritter et al, ${ }^{20}$ tests performed in both sanded and non-sanded enamel surfaces did not present statistically significant differences in the adhesive strength values. Although the sanding is responsible for a flatter bonding surface, not sanding the samples was justifiable for the present study aims at assessing the physical 
properties of primers on enamel. Considering the variability of enamel thickness, ${ }^{11}$ were teeth surfaces to be sanded, there would be a great risk of reaching the dentin, with considerably different physical and chemical properties form enamel ones.

In this way, result differences observed in many research works may be due to the different work methodologies, or to the different type of teeth used (bovine or human); ${ }^{15}$ teeth storage after extraction; if thermo cycling is performed or not; sample specimens manufacturing procedures; treatments applied to enamel; ${ }^{4}$ time and type of acid etchant; ${ }^{22}$ differences between materials used in the work such as primers, adhesive systems and brackets; ${ }^{8}$ mechanical assay machinery for testing and load cell applied to the bracket; ${ }^{12,18}$ after test storage material and period, amongst others. All these variables make it difficult to compare research's absolute results with one another and, for that reason, what should be taken in to account when comparing such values is the statistic significance of the adhesive strengths.

During result assessment, Ortho Primer Morelli ${ }^{\circledR}$ Group was proven to have a higher adhesive strength value, corresponding to $8.54 \pm 1.86 \mathrm{MPa}$ (p $<0.05$ ), when compared to the other two groups tested, which presented $6.83 \pm 2.05 \mathrm{MPa}$ (Transbond $\mathrm{XT}^{\circledR}$ Primer Group) and $6.42 \pm 2.12 \mathrm{MPa}$ (Transbond $\mathrm{XT}^{\circledR}{ }^{\circledR}$ without Primer Group). This adhesive strength increase is even higher than the upper limit recommended by Reynolds, ${ }^{19}$ in 1975, who suggests that adhesive strengths varying between 6.0 and 8.0 MPa would suffice.

These results mean that the adhesive strength promoted by Ortho Primer Morelli ${ }^{\circledR}$ is higher than the conventional system ones, just as described by Harari et al, ${ }^{9}$ in 2000, when they tested High-QBond adhesion promoting primer, comparing it to the Right-On conventional adhesive system. The authors obtained a higher average adhesive strength for High-Q-Bond, for brackets bonded on both enamel 9.90 $\pm 2.09 \mathrm{MPa}$ and amalgam $6.89 \pm 1.82 \mathrm{MPa}$, against $8.29 \pm 3.18 \mathrm{MPa}$ and $5.48 \pm 1.77 \mathrm{MPa}$, respectively, obtained with Right-On.

In another work from 2002, Harari, Gillis and Redlich ${ }^{10}$ observed that groups where an bond enhancing primer was used presented a satisfactory adhesive strength for the orthodontic practice, even though no acid etching was performed, using Reynolds ${ }^{19}$ parameters, as an alternative to decrease the number of steps during the orthodontic bracket bonding procedure.

Grandhi, Combe and Speidel, ${ }^{8}$ in 2001, have also obtained higher results during shear tests for the bond enhancing primer when tested Transbond MIP primer with Transbond XT composite resin, the same way did Mavropoulos et al, ${ }^{14}$ in 2003, when tested Transbond MIP primer, comparing it to a chemically cured Unite composite resin. Vicente et al, ${ }^{25}$ in 2006, also obtained statistically significant higher values in adhesive strength tests for the groups where Enhance-LC adhesion promoting primer was used, especially when it was used together with the Light-Bond system as recommended by the manufacturer.

Grandhi, Combe and Speidel ${ }^{8}$ observed satisfactory adhesive strength results with Transbond XT composite resin associated to a moisture tolerant primer, in a moist environment. Nevertheless, the authors do not recommend the use of the same primer together with the Concise chemically cured composite resin since the hydrophobic nature of the composite repels the MIP primer. They suggest its should only be used with light cured composite resins.

Vicente et $\mathrm{al}^{24}$ in their work of assessment of the adhesive strength of the Enhance-LC bonding promotion agent, have found values that are way beyond those recommended for Orthodontic purposes, according to Reynolds parameters. Authors have advised it should only be used in non-compliant patients to the orthodontic therapy or in places where moist control is very difficult, which need a higher bracket adhesive strength. Such statements end up encouraging further research with Ortho Primer Morelli ${ }^{\circledR}$ in wet environments.

Wegner, Deacon and Harradine, ${ }^{26}$ in 2008, compared the Orthosolo bond enhancing agent to the conventional Transbond XT system and found no statistic difference in the adhesive strength assessment between conventional systems and bond enhancing agents, pretty much as Coreil et al, ${ }^{5}$ Chung et $\mathrm{al}^{4}$ and Owens and Miller ${ }^{18}$ in their respective works. Coreil et al, ${ }^{5}$ nonetheless, have performed the bonding in human teeth with sanded surfaces. Chung et $\mathrm{al}^{4}$ obtained an increase in the adhesive strength after the tests were done using primer 
only for the re-bonded brackets group. For the new brackets group, there was no statistic difference between the two systems.

Results reporting a decrease in the adhesive strength in groups where a bond enhancing primer was used were found by Littlewood et al, ${ }^{12}$ diverging from the results obtained in the present study. According to the afore mentioned authors, these results may be due to the fact that primers are hydrophilic and the tests were performed on dry conditions, under the justifying argument that standardization is hard to be achieved in wet test environments.

Littlewood, Mitchell and Greenwood, ${ }^{13}$ compared a traditional primer and a hydrophilic orthodontic primer and observed a decrease in the adhesive strength for bracket bonding when compared to a conventional system primer, used with Transbond XT composite resin. They have recommended that hydrophilic primers should only be used in places where the moisture control is hard to obtain.

Since all works quoted, as well as the present study, were performed in vitro, it is advisable that further studies should check on the clinical feasibility of Ortho Primer Morelli ${ }^{\circledR}$, such as Mavropoulos et $\mathrm{al}^{14}$ did in a research preformed using Transbond MIP primer.

Flaw sites are as important as the adhesive strength of a given material. When using primers, the goal is to increase the adhesive strength to a limited extent, since far too high of an adhesive strength may cause damages to enamel structures during bracket removal. ${ }^{24}$ One of the methods used in order to assess material behaviour when brackets come loose is the Remaining Adhesive Index (RAI), created by Årtun and Bergland, ${ }^{1}$ in 1984, and applied to the present work.

During the RAI analysis performed in the present work, both the system which used the conventional system primer and Ortho Primer Morelli ${ }^{\circledR}$ presented a prevalence in the fracture site taking place between the bracket and the bonding agent (adhesive), with $90 \%$ and $87 \%$ of test specimens presenting scores 2 and 3, respectively. There was no statistically significant difference of RAI between groups. This adhesive flaw between composite and bracket was also found in other studies. ${ }^{4,5,10,12}$

Results differing from the ones presented here were described by Harari et al, ${ }^{9}$ Owens and Miller ${ }^{18}$ and Mavropoulos et al, ${ }^{14}$ who have verified a lower RAI in the groups where bond enhancing primers were applied, which means that the flaw took place in the enamel/bond interface. Vicente et al, ${ }^{24,25}$ in their works where Enhance-LC primer was tested, no statistically significant difference was observed between the remaining composite indexes between the control and the groups where the bond enhancing agent was used.

For many authors ${ }^{4,5,9,10,12,14,18}$ the adhesive failure between the adhesive and the bracket is a drawback, for during the removal of the remaining adhesive there could be enamel wearing. For this reason, the best case scenario, according to the authors, would have the remaining adhesive left at the base of the bracket instead of at the enamel surface.

Nevertheless, according to Shojaei et al, ${ }^{23}$ if the flaw happens in the enamel/adhesive interface, the likelihood of a tooth fracture event is higher, and the ideal would be flaws taking place between the bonding agent and the bracket, with the remaining adhesive being carefully removed by the dentist. In spite of that, Harari et al, ${ }^{9}$ Owens and Miller ${ }^{18}$ and Mavropoulos et $\mathrm{al}^{14}$ consider the enamel/adhesive failure as a positive issue, once after bracket removal the enamel is adhesive free and saves further interventions with instruments that could damage the enamel structure.

The present work used a group where the adhesive paste was directly applied on the etched enamel surface without any primer: Transbond $\mathrm{XT}^{\circledR}$ without Primer Group. None of the works found in the literature review did this comparison. With regards to the adhesive strength, this group obtained values ( $p>0.05$ ) that are statistically equivalent to the group that used the conventional primer (Transbond XT ${ }^{\circledR}$ Primer Group).

When it comes to the adhesive failure, Transbond $\mathrm{XT}^{\circledR}$ without Primer Group presented 57\% of flaws in the enamel/adhesive interface (scores 0 and 1 ) and $43 \%$ in the adhesive/bracket interface (scores 2 and 3), presenting significant statistic differences $(p<0.05)$ vis a vis to the groups that used primers (Transbond $\mathrm{XT}^{\circledR}$ Primer Group and Ortho Primer ${ }^{\circledR}$ Group) (Fig 4).

It is suggested that the use of primers within the conventional system is not recommended for an increase in the adhesive strength but rather to a better 
predictability of the failure location taking place in the adhesive/bracket interface.

This study revealed no correlation between the adhesive strength and the site of the adhesive failure, in other works, an increased adhesive strength does not necessarily imply a higher bonding between enamel and adhesive.

The use of bond enhancing agents in orthodontics as an attempt to achieve better results in terms of adhesive strength in bonding brackets has become increasingly frequent in orthodontic practice and has presented favorable outcomes ${ }^{8,9,10,25}$. Another favorable issue with regards to the use of these primers is the fact that they cause no harm to the enamel during bracket removal ${ }^{4,5,10,12}$.

In the present paper, Ortho Primer Morelli ${ }^{\circledR}$ has proven to be quite a promising material. From the results gathered in this in vitro study, it is suggested that further research with Ortho Primer Morelli ${ }^{\circledR}$ should be performed in an in vivo setting.

\section{CONCLUSION}

With the present results, we can conclude that:

» Ortho Primer Morelli ${ }^{\circledR}$ bond enhancing primer increases adhesive strength when compared to the conventional adhesive system.

» Ortho Primer Morelli ${ }^{\circledR}$ bond enhancing primer presents the same failure site to the conventional adhesive system, that is the adhesive/bracket interface.

» The single use of Transbond $\mathrm{XT}^{\circledR}$ adhesive system paste presents the same adhesive strength when compared to the conventional adhesive system.

» The single use of Transbond $\mathrm{XT}^{\circledR}$ adhesive system paste does not allow one to foresee the site of the adhesive failure.

» There is no correlation whatsoever between adhesive strength and the adhesive failure location, regardless of the use of any bond enhancing agent. 


\section{REFERENCES}

1. Artun J, Bergland S. Clinical trials with crystal growth conditioning as an alternative to acid etch enamel pretreatment. Am J Orthod. 1984 Apr;85(4):333-40.

2. Bishara SE, Gordan VV, VonWald L, Jakobsen JR. Shear bond strength of composite, glass ionomer, and acidic primer adhesive systems. Am J Orthod Dentofacial Orthop. 1999 Jan;115(1):24-8.

3. Buonocore MG. A simple method of increasing the adhesion of acrylic filling materials to enamel surface. J Dent Res. 1955 Dec;34(6):849-53.

4. Chung $\mathrm{CH}$, Fadem BW, Levitt HL, Mante FK. Effects of two adhesion boosters on the shear bond strength of new and rebounded orthodontic brackets. Am J Orthod Dentofacial Orthop. 2000 Sep;118(3):295-9.

5. Coreil MN, McInnes-Ledoux P, Ledoux WR, Weinberg R. Shear bond strength of four orthodontic bonding systems. Am J Orthod Dentofacial Orthop. 1990 Feb;97(2):126-9

6. Eliades G, Palaghias G, Vougiouklakis G. Surface reactions of adhesives of dentin. Dent Mater. 1990 Jul;6(3):208-16.

7. Fox NA, McCabe JF, Buckley JG. A critique of bond strength testing in orthodontics. Br J Orthod. 1994 Feb;21(1):33-43.

8. Grandhi RK, Combe EC, Speidel TM. Shear bond strength of stainless steel orthodontic brackets with a moisture-insensitive primer. Am J Orthod Dentofacial Orthop. 2001 Mar;119(3):251-5.

9. Harari D, Aunni E, Gillis I, Redlich M. A new multipurpose dental adhesive for orthodontic use: An in vitro bond-strength study. Am J Orthod Dentofacial Orthop. 2000 Sep;118(3):307-10.

10. Harari D, Gillis I, Redlich M. Shear bond strength of a new dental adhesive used to bond brackets to unetched enamel. Eur J Orthod. 2002 Oct;24(5):519-23.

11. Iwasa E, Cotrim-Ferreira FA, Scavone-Junior H, Tormin ACF, Boldrini SC, Velini F. Correlações entre medidas da coroa e a espessura do esmalte nas faces proximais de incisivos superiores permanentes humanos. Rev Odontol UNICID. 2002 SetDez;14(3):163-71.

12. Littlewood SJ, Mitchell L, Greenwood DC, Bubb NL, Wood DJ. Investigation of a hydrophilic primer for orthodontic bonding: an in vitro study. J Orthod. 2000 Jun;27(2):181-6

13. Littlewood SJ, Mitchell L, Greenwood DC. A randomized controlled trial to investigate brackets bonded with a hydrophilic primer J Orthod. 2001 Dec;28(4):301-5
14. Mavropoulos A, Karamouzos A, Kolokithas G, Athanasiou AE. In vivo evaluation of two new moisture-resistant orthodontic adhesive systems: a comparative clinical trial. J Orthod. 2003 Jun;30(2):139-47; discussion 127-8.

15. Nakamichi I, Iwaku M, Fusayama T. Bovine teeth as possible substitutes in the adhesion test. J Dent Res. 1983 Oct;62(10):1076-81.

16. Newman GV. Epoxy adhesives for orthodontic attachments: progress report. Am J Orthod. 1965 Dec;51(12):901-12

17. Oesterle LJ, Shellhart WC, Belanger GK. The use of bovine enamel in bonding studies. Am J Orthod Dentofacial Orthop. 1998 Nov;114(5):514-9.

18. Owens SE Jr, Miller BH. A comparison of shear bond strengths of three visible lightcured orthodontic adhesives. Angle Orthod. 2000 Oct;70(5):352-6.

19. Reynolds IR. A review of direct orthodontic bonding. Br J Orthod. 1975;2(3):171-8.

20. Ritter DE, Ritter AV, Bruggeman G, Locks A, Tulloch JF. Bond strengths and adhesive remnant index of self-etching adhesives used to bond brackets to instrumented and uninstrumented enamel. Am J Dent. 2006 Feb;19(1):47-50.

21. Rodriguez GCD, Carvalho PAL, Horliana RF, Bomfim RA. Avaliação "in vitro" da resistência à tração de bráquetes metálicos colados com o novo sistema adesivo "self etching primer" (SEP). Ortodontia. 2002 Abr-Jun;53(2):28-34.

22. Sadowsky PL, Retief DH, Cox PR, Hernández-Orsini R, Rape WG, Bradley EL. Effects of etchant concentration and duration on the retention of orthodontic brackets: an in vivo study. Am J Orthod Dentofacial Orthop. 1990 Nov;98(5):417-21.

23. Shojaei AR, Thompson BD, Kulkarni GV, Titley KC. Adhesive remnant index (ARI) revisited. An in vitro assessment of clinically debonded orthodontic brackets. Am J Orthod Dentofacial Orthop. 2006 Jul;130(1): 120.

24. Vicente A, Bravo LA, Romero M, Ortíz AJ, Canteras M. Bond strength of brackets bonded with an adhesion promoter. Br Dent J. 2004 Apr 24;196(8):482-5; discussion 469 .

25. Vicente A, Bravo LA, Romero M, Ortíz AJ, Canteras M. Effects of 3 adhesion promoters on the shear bond strength of orthodontic brackets: an in-vitro study. Am J Orthod Dentofacial Orthop. 2006 Mar;129(3):390-5.

26. Wenger NA, Deacon S, Harradine NW. A randomized control clinical trial investigating orthodontic bond failure rates when using Orthosolo universal bond enhancer compared to a conventional bonding primer. J Orthod. 2008 Mar;35(1):27-32. 